\title{
The analysis of repeatability and reproducibility of bladder neck mobility measurements obtained during pelvic floor sonography performed introitally with a 2D transvaginal probe
}

\author{
Edyta Wlaźlak ${ }^{1}$, Tomasz Kluz $^{2}$, Jacek Kociszewski ${ }^{3}$, Karolina Frachowicz', \\ Magdalena Janowska ${ }^{2}$, Wiktor Wlaźlak ${ }^{1}$, Grzegorz Surkont ${ }^{1}$ \\ ${ }^{1}$ Clinic of Operative Gynecology and Gynecologic Oncology, $1{ }^{\text {st }}$ Department of Gynecology and Obstetrics, \\ Medical University of Lodz, Poland \\ ${ }^{2}$ Department of Gynecology and Obstetrics, Chopin Hospital of Rzeszow, Poland \\ ${ }^{3}$ Department of Gynecology and Obstetrics, Lutheran Hospital Hagen-Haspe, Hagen, Germany
}

\begin{abstract}
Objectives: The aim of the study was the evaluation of repeatability and reproducibility of chosen urethral neck mobility measurements obtained during introital pelvic floor sonography performed with a 2D transvaginal probe.

Material and methods: In order to assess the repeatability and reproducibility, independent measurements on the ultrasound image were taken by two specialists on 92 female patients at rest and at strain (Valsalva maneuver). 2D ultrasound examination was performed introitally with a transvaginal probe (PFS-TV). The location of the urethral internal orifice was defined with coordinates of two points. Point $\mathrm{Cl}$ marks the urethral anterior edge visualized on ultrasound as closer to the pubic symphysis. Point Cll marks the posterior edge visualized more peripherally from pubic symphysis.

Results: Repeatability and reproducibility measurements of point $\mathrm{Cl}$ location and mobility were good and very good (0.6710-0.9961), while of point CII — were medium, good and very good (0.5738-0.9944). Point Cl was clearly visible in all cases. It was not possible to accurately mark point $\mathrm{Cll}$ in $4.3-17.4 \%$ of cases.

Conclusions: The possibility to visualize point $\mathrm{Cl}$ in every single case with very good and good repeatability and reproducibility of measurements of this point's location and mobility allows the usage of $\mathrm{Cl}$ point as a universal reference point for evaluation of bladder neck mobility and position during PFS-TV in the clinical practice and for research purposes.
\end{abstract}

Key words: urogynecology, pelvic floor ultrasound, transvaginal probe, urethral mobility, repeatability

Ginekologia Polska 2017; 88, 7: 360-365

\section{INTRODUCTION}

Experts agree that patients with urodynamic stress urinary incontinence (SUI) fall into several groups depending on the urethral support and its functions. Many authors use Blaivas' classification of SUI, which is based on the bladder base position in relation to the inferior margin of the pubic symphysis (IMPS), and whether or not the bladder neck $(B N)$ is open at rest (Table 1). The progress in direct studies of urethra and the usage of advanced imaging modalities (i.e. MRI and real time ultrasonography), will probably soon result in new classification of SUI, which could link hypermobility and urethral dysfunction as inter-related elements [1].

The differences in the urethral support may have an impact on urethral mobility [1]. Many urogynecologists consider assessment of bladder neck mobility important enough to include it in the pre-operative diagnostics [2-4]. Despite the consensus on the importance of bladder neck mobility, there is disagreement about the assessment methods to be used [3,4]. The usefulness of imaging is doubtful as supporting data available in the literature is very scant [5]. Another 
Table 1. Blaivas' classification of SUI

\begin{tabular}{|c|l|}
\hline SUI type & Description \\
\hline & $\begin{array}{l}\text { Normal position above IMPS } \\
\text { BN closed at rest } \\
\text { Leakage and descent }<2 \text { cm below IMPS }\end{array}$ \\
& $\begin{array}{l}\text { Normal position } \\
\text { BN closed } \\
\text { Rotational descent (cystourethrocoele) } \\
\text { IIb }=\text { abnormally low position at rest }\end{array}$ \\
\hline \multirow{2}{*}{$\quad \begin{array}{l}\text { Normal position } \\
\text { BN open at rest } \\
\text { Previously intrinsic sphincter deficiency (ISD) }\end{array}$} \\
\hline
\end{tabular}

method used to assess the urethral mobility is a Q-tip test. It involves inserting a sterile lubricated cotton swab directly into the urethra to the proximity of the urethral internal orifice. Movement of the Q-tip of more than 30 degrees from horizontal during strain is indicative of hypermobility of the bladder neck. However, normobility and hypomobility in this test have not been defined yet [6]. Similarly, the usefulness of the POP-Q scale to evaluate the mobility of the bladder neck and urethra has been denied by most of researchers [5-8]. Cystourethrography in turn allows accurate assessment of the bladder neck and urethral mobility. The usefulness of the radiological cystourethrography to detect bladder neck hypermobility is well documented. Again however, hypomobility of urethra is not defined in this test while its invasiveness and exposure to radiation led to a search for alternative methods of evaluating urethral mobility [5, 9].

In contrast to urethral hypermobility, hypomobile urethra with urodynamic features of intrinsic sphincter deficiency (ISD) has been for years regarded as an important risk factor for failure of surgical intervention in SUI patients [6, 10]. The reason for this is not fully understood. ISD and hypomobile urethra remain not clearly defined [2, 3, 8, 11-13].

Pelvic floor ultrasound is becoming increasingly more popular in urogynecology. The measurements of small pelvis structures with USG showed good reproducibility [11-14]. Dietz et al. showed that the ultrasound perineal evaluation of bladder neck mobility performed with a transabdominal probe has a good reproducibility, even if repeated 32-122 days after the first test $[15,16]$. Recent studies show that pelvic floor sonography performed with 2D transvaginal probe (PFS-TV) may detect patients with reduced bladder neck mobility while such condition had a negative impact on the results of SUI surgery with suburethral tape implantation, even when the surgery was individually planned. In turn, patients with normomobile and hypermobile urethra detected with PFS-TV had a much higher chance of successful SUI correction, even if the tape was suboptimally placed [17-19]. However, the repeatability and reproducibility of the analysis of bladder neck mobility with PFS-TV has not been established yet.

\section{OBJECTIVES}

The aim of this study is to evaluate the repeatability and reproducibility of certain bladder neck mobility measurements obtained with PFS-TV.

\section{MATERIAL AND METHODS}

The analysis is based on the imaging results of 92 urogynecologic patients who agreed to participate in the study. The Ethics Committee has approved this study.

Based on previous studies [20] the internal urethral orifice location was analyzed in XOY coordinate system, the center of which was fixed to the lower outer edge of patient's symphysis pubis (point $O$ on Fig. 1). $C_{y}$ coordinate reflects the position of point $\mathrm{C}$ on the $\mathrm{OY}$ axis. Segment $\mathrm{H}$ was defined as the distance $C_{y}$ from point $O . C_{x}$ is a projection of point $C$ on the axis OX. Segment $D$ is defined as the distance $C_{x}$ from point $O$.

For a clearer visualization of individual points and segments they were named in the following way:

- location at rest: $\mathrm{Cl}, \mathrm{Cll}, \mathrm{HI}, \mathrm{DI}, \mathrm{HII}$, DII (Fig. 1),

- location at maximum Valsalva maneuver: $\mathrm{Cl}_{p^{\prime}} \mathrm{ClI}_{p^{\prime}}, \mathrm{HI}_{p^{\prime}}$ $\mathrm{DI}_{p^{\prime}} \mathrm{HII}_{\mathrm{p}^{\prime}}$ DII (Fig. 1).

As opposed to previous studies [17-19], our location of the internal urethral orifice is defined with two points; point $\mathrm{Cl}$ is the more anterior edge of the internal urethral orifice, visualized in the ultrasound image as closer to the pubic symphysis. Point $\mathrm{Cll}$ is the more posterior edge of the urethral internal orifice visualized more peripherally. Segments $\mathrm{HI}$ and DI determine the location of the point $\mathrm{Cl}$, while HII and DII of the point CII respectively (Fig. 1).

Quantitative parameters of the internal urethral orifice mobility were determined during rest and strain evoked with Valsalva maneuver (Fig. 1). For quantitative determination of the urethral mobility two parameters were assumed: bladder neck descent distance (BND) and the vector parameter in the XOY coordinate system (Fig. 1).

BND parameter is used for direct evaluation of the bladder neck mobility in the vertical axis $[10,20]$. It is defined as the descent of the point $\mathrm{C}$ along the $\mathrm{Y}$-axis during Valsalva maneuver, cough or Kegel's exercise (Fig. 1). The $\mathrm{Cl}$ and Cll point of BND at strain is named $B N D I_{p}$ and $B N D \|_{p}$ respectively.

The vector was calculated according to the formula (1) in conformity with the method used by Viereck [20] as the hypotenuse of a perpendicular triangle, the sides of which are the segments $\Delta \mathrm{D}$ and $\Delta \mathrm{H}$ (Fig. 1):

$$
\text { Vector }=\operatorname{sqrt}\left(\Delta \mathrm{H}^{2}+\Delta \mathrm{D}^{2}\right)
$$

The $\Delta \mathrm{H}$ value was calculated from the formula (2): $\Delta \mathrm{H}=\mathrm{H}-\mathrm{H}_{\mathrm{p}}$

The $\Delta \mathrm{D}$ value was calculated from the formula (3): $\Delta \mathrm{D}=\mathrm{D}-\mathrm{D}_{\mathrm{p}}$ 
A
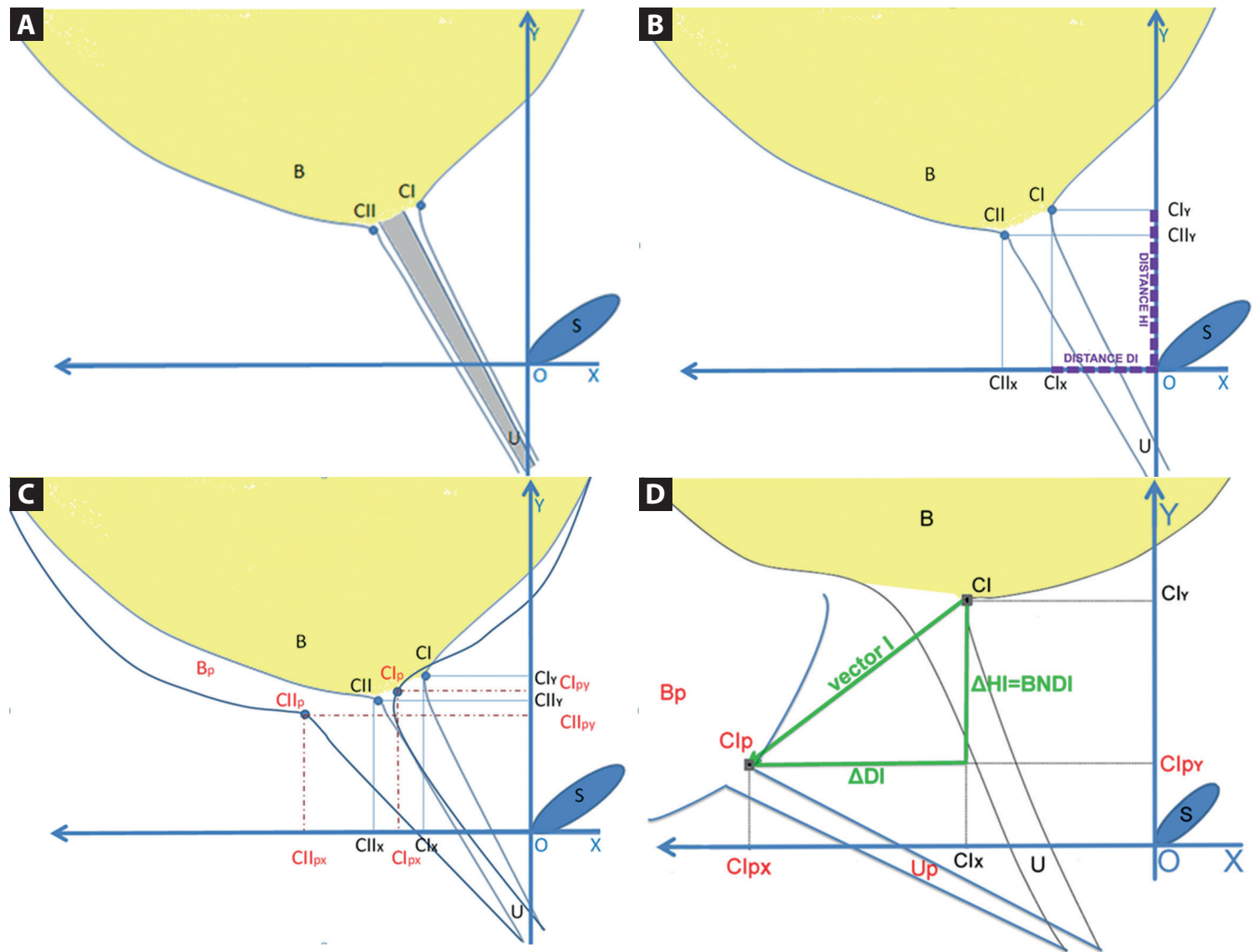

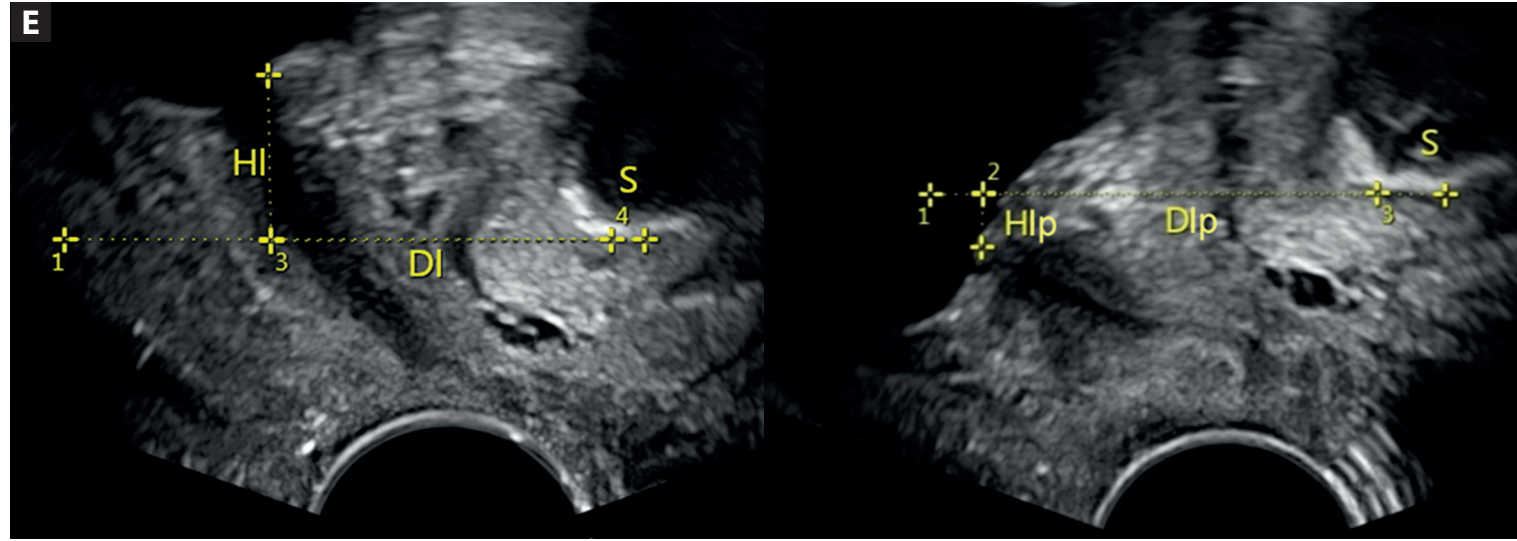

Figure 1. Diagram of the internal urethral orifice sonographic parameters at rest and at Valsalva maneuver. A. Location of the $\mathrm{Cl}$ and $\mathrm{Cll}$ points within the internal urethral orifice; $\mathbf{B}$. Location of the $\mathrm{Cl}$ and $\mathrm{Cll}$ points on the OY and OX axis; $\mathbf{C}$. Location of the $\mathrm{Cl}$ and $\mathrm{Cll}$ points (at rest) and $\mathrm{Cl}_{\mathrm{p}}$ and $\mathrm{Cll}_{\mathrm{p}}$ points (at Valsalva maneuver) on the OY and OX axis; D. Calculation of internal urethral orifice mobility parameters: BND and vector; E. The ultrasound images: on the left $=$ at rest and on the right $=$ at Valsalva maneuver

Legend: $\mathrm{S}$ - pubic symphysis; $\mathrm{B}$ - bladder; $\mathrm{U}$ - urethra; $\mathrm{Cl}$ and $\mathrm{Cll}$ - points referring to the internal urethral orifice at rest; $\mathrm{Cl}$ and $\mathrm{Cll}$ - projection of the $\mathrm{Cl}$ and $\mathrm{Cll}$ points on the $\mathrm{OX}$ axis; $\mathrm{Cl}_{\mathrm{y}}$ and $\mathrm{Cll}_{\mathrm{y}}$ — projection of the $\mathrm{Cl}$ and $\mathrm{Cll}$ points on the OY axis; $\mathrm{B}_{\mathrm{p}}$ - bladder at maximum Valsalva maneuver; $\mathrm{Cl}_{\mathrm{p}}$ and $\mathrm{Cll}{ }_{\mathrm{p}}$ — points locating the internal urethra orifice during Valsalva maneuver; $\mathrm{Cl}_{\mathrm{px}}$ and $\mathrm{Cll}$ px - projection of the $\mathrm{CIP}$ and CIIP points on the OX axis; $\mathrm{Cl}_{\mathrm{py}}$ and $\mathrm{Cll}_{\mathrm{py}}$ — projection of the CIP and CIIP points on the OY axis; $\Delta \mathrm{HI}$ - parameter BND for the Cl point at Valsalva maneuver; Vector I - vector parameter for the Cl point at Valsalva maneuver

The vector's originating point $\mathrm{Cl}$ or Cll during Valsalva maneuver is named vector $I_{p}$ or vector $I_{p}$ respectively.

Pelvic floor sonography was performed on a B-K Pro Focus Ultra View machine with a transvaginal transducer $8848,2 \mathrm{D}, 6,5 \mathrm{MHz}$ frequency by professionals experienced in gynecological and urogynecological examinations. The measurements were performed with an accuracy of the ultrasound machine to $0.1 \mathrm{~mm}$. 2D-ultrasound tests were performed at rest and during maximum Valsalva maneuver.

PFS-TV was performed introitally with standardized technique developed by Kociszewski $[17,18]$ using a transvaginal probe of high-frequency $\left(6.5 \mathrm{MHz}, 160^{\circ}\right.$ beam angle 
ultrasound) in a semi-sitting position of the patient on a gynecological chair. The probe was placed in line with the patient's axis, maintaining minimal pressure of the probe on the tested area. Symphysis pubis (which was the only fixed point of reference), the urethra and the bladder neck were visualized within the screen and measurements determining the location of points $\mathrm{Cl}$ and $\mathrm{Cll}$ were made (Fig. 1).

Statistical analysis was performed in Statistica version 7.1 StatSoft Poland. To evaluate the limits of agreement, Bland-Altman agreement scale was applied. ICC values $<0.20$ were considered as poor, those in the range of $0.21-0.41$ as fair, $0.41-0.60$ as moderate, $0.61-0.80$ as good, and $0.81-1.00$ as excellent $[14,21]$.

For the sake of the analysis of reproducibility and repeatability of bladder neck mobility measurements, every specialist took four images on the same patient (two at rest and two during maximal Valsalva). For every of the four above-mentioned ultrasound images, measurements were repeated twice by each specialist.

\section{RESULTS}

\section{Data analysis of measurements} from the same ultrasound image

The analysis of measurements of HI, DI, DII and HII taken at rest show high conformity. The biggest compliance was obtained for the $\mathrm{HI}$ and DI (Table 2). Point $\mathrm{Cl}$ was clearly visible in each of the patients, which allowed each doctor to take accurate measurements. Point CII in contrast (more distal to symphysis pubis) could not be clearly visualized (to the extent it was not possible to determine the location of this point) in $4.3 \%(n=4)$ of observations. Therefore, the data

\begin{tabular}{|c|c|c|c|}
\hline & A & B & $A$ and $B$ \\
\hline $\mathrm{HI}$ & 0.9961 & 0.9843 & 0.9696 \\
\hline DI & 0.9903 & 0.9942 & 0.8874 \\
\hline HII & 0.9944 & 0.9563 & 0.9373 \\
\hline DII & 0.9855 & 0.9794 & 0.7803 \\
\hline $\mathrm{HI}_{\mathrm{p}}$ & 0.9962 & 0.9884 & 0.9775 \\
\hline $\mathrm{DI}_{\mathrm{p}}$ & 0.9859 & 0.9550 & 0.9109 \\
\hline $\mathrm{HII}_{\mathrm{p}}$ & 0.9687 & 0.9821 & 0.9330 \\
\hline DII $_{p}$ & 0.9708 & 0.8901 & 0.8052 \\
\hline Vector $I_{p}$ & 0.9731 & 0.9834 & 0.9372 \\
\hline Vector $\|_{p}$ & 0.7923 & 0.9569 & 0.8598 \\
\hline $\mathrm{BNDI}_{\mathrm{p}}$ & 0.9712 & 0.9887 & 0.9342 \\
\hline$B N D \|_{p}$ & 0.9455 & 0.9722 & 0.9121 \\
\hline
\end{tabular}

Legend: $A$ - specialist $A ; B$ - specialist $B ; A$ and $B$ - comparison between specialist $A$ and $B$ related to accuracy of measurements of $\mathrm{HII}$ and DII referred to a total of 88 patients.

Reproducibility and repeatability of parameters $\mathrm{HI}_{\mathrm{p}^{\prime}} \mathrm{DI}_{\mathrm{p}^{\prime}}$ $\mathrm{HII}_{\mathrm{p}^{\prime}} \mathrm{DII}_{\mathrm{p}}$ (at maximal Valsalva maneuver) was very good. The biggest conformity was obtained for $\mathrm{HI}_{\mathrm{p}}$ and $\mathrm{DI}_{\mathrm{p}}$ (Table 2). Like before, point $\mathrm{Cl}$ was well visible allowing for measurements with high repeatability and reproducibility while point Cll could not be clearly visualized in $14.1 \%$ (doctor $A$, $n=13$ ) and $15.2 \%$ (doctor $B, n=14$ ) of patients.

Reproducibility and repeatability of the vector $I_{p}$ and of the BND $I_{p}$ was better than that of $\|_{p}$ and BND $\|_{p}$ for both: same doctor (intra-observer) and between doctors (inter-observer) (Table 2). A worse visualization of the $\mathrm{Cll}_{\mathrm{p}}$ parameter could adversely affected the measurement accuracy and repeatability of these results.

\section{Data analysis of measurements from two ultrasound images obtained in a short space of time}

The biggest conformity of measurements taken on different images was for distances $\mathrm{HI}$ and DI (Table 3). Measuring $\mathrm{HIl}$ and DII was not possible in 4 cases only.

$\mathrm{HI}_{\mathrm{p}}$ and $\mathrm{DI} \mathrm{p}_{\mathrm{p}} \cdot \mathrm{HII}_{\mathrm{p}}$ and $\mathrm{DI} \mathrm{p}_{\mathrm{p}}$ were characterized by a good repeatability and reproducibility when measured by both specialists $A$ and $B$ (Table 3). While parameters $\mathrm{HI}_{\mathrm{p}}$ and $\mathrm{DI}_{\mathrm{p}}$ were obtainable with no exception, measuring $\mathrm{HII}_{\mathrm{p}}$ and DII failed in $15.2 \%$ (doctor $A, n=14$ ) and $17.4 \%$ of cases (doctor $B, n=16$ ) due to lack of satisfactory visualisation of point $\mathrm{Cll}_{\mathrm{p}}$. In such cases the picture of $\mathrm{Cll}$ was rounded and blurred probably because of the distal localization on the ultrasound beam. The data from those patients was not analyzed.

Table 3. Correlation of the ultrasound parameters locating the internal urethral orifice obtained at two different ultrasound images

\begin{tabular}{|c|c|c|c|}
\hline & A & B & A and B \\
\hline $\mathrm{HI}$ & 0.8581 & 0.8170 & 0.8549 \\
\hline $\mathrm{DI}$ & 0.8090 & 0.6604 & 0.7428 \\
\hline $\mathrm{HII}$ & 0.8187 & 0.7190 & 0.8137 \\
\hline $\mathrm{DII}$ & 0.7179 & 0.6086 & 0.6733 \\
\hline $\mathrm{H}_{\mathrm{p}}$ & 0.8515 & 0.8235 & 0.8785 \\
\hline $\mathrm{DI}$ & 0.7146 & 0.7641 & 0.8059 \\
\hline $\mathrm{H} \|_{p}$ & 0.7904 & 0.7468 & 0.8070 \\
\hline $\mathrm{D} \|_{p}$ & 0.5907 & 0.7049 & 0.6242 \\
\hline Vector $I_{p}$ & 0.6710 & 0.7008 & 0.7189 \\
\hline Vector $\|_{p}$ & 0.5738 & 0.6237 & 0.6105 \\
\hline BND I & 0.6934 & 0.7003 & 0.7404 \\
\hline BND $\|_{p}$ & 0.5794 & 0.6253 & 0.6188 \\
\hline
\end{tabular}

Legend: $A$ - specialist $A ; B$ - specialist $B ; A$ and $B$ - comparison between specialist $A$ and $B$ 
Repeatability and reproducibility of vector $I_{p}$ and the BND I was good. It was better than vector $\|_{p}$ and BND $\|_{p^{\prime}}$ of which repeatability and reproducibility was medium and good.

\section{DISCUSSION}

Although many urogynecologists believe that the bladder neck mobility assessment should be included into the preoperative diagnostics of each urogynecological patient [2-4], there is no consensus on the measuring method [2,3]. In many centers no assessment is performed at all. The clinical relevance of urethral mobility in the evaluation of urodynamic SUI has been a source of controversy for years [22].

Different methods have been used to evaluate urethral mobility. The reproducibility of urethral mobility visual assessment was not examined. This assessment is biased with a high degree of subjectivity [5]. The results of a few studies concerning the usefulness of Q-tip test are controversial. Thorp et al. believe that the Q-tip test is characterized by a good reproducibility and repeatability [7]. There are specialists who question the usefulness of this test. Shek and Dietz believe that the Q-tip test can reflect only the artifacts because the urethra during Valsalva test does not behave as a straight non-elastic tube [8]. The test itself is technically simple to perform. Unfortunately, it often causes discomfort to the patient while inserting the Q-tip to the urethra near the bladder neck, which may negatively affect the results [5]. POP-Q scale is not used to assess the bladder neck and urethral mobility [5]. Radiological cystourethrography is currently rarely performed due to its invasiveness [5]. Compared to such diagnostic methods, pelvic floor ultrasound has many advantages. Ultrasound machines are found practically in all gynecological and urological departments. The examination is cheap, non-invasive, allows real time visualization and multiple repetitions, has a very good resolution and allows 2D, 3D and 4D imaging. This is the reason why it is nowadays used in urogynecologic patients more often [17, $23,24]$. The urethral mobility assessment performed with transperineal 2D ultrasound imaging with a transabdominal probe confirmed good reproducibility of similar measurements $[15,16,25,26]$. A comparison of three different methods of measuring urethrovesical mobility showed that the Q-tip test and the Sensor-Q had higher inter-observer reliability of urethral mobility evaluation than the ultrasound method [22]. Sensor-Q allows assessing electronically the change between the urethral axis at rest and at Valsalva producing a graph printout as a result. However, Sensor-Q is not available now [22]. The authors did not provide information about the degree of experience of the specialists in the study, which could have negatively influenced the results. In another study the Q-tip test was compared with the ultrasound. Authors concluded that the Q-tip test was inaccurate for measurement of urethrovesical junction mobility and should not be used in the manner described to diagnose urethrovesical junction hypermobility [27].

Several sonographic approaches have been used for the study of urogynecologic symptoms: suprapubic, translabial, transvaginal, transperineal, introital, 2D, 3D and 4D $[1,13,19]$. There is no consensus on optimal approach to be used for different situations. Also, no comparison was performed between different approaches [1]. PFS-TV is one of the methods recently applied to urogynecology [17-19]. Recent clinical studies on PFS-TV have confirmed the adverse effect of the $\mathrm{Cl}$ point hypomobility on SUI cure rate after implantation of suburethral tape [17-19]. The results of these studies have led to definitions of hypomobile, normomobile and hypermobile urethra based on the value of the vector parameter [19]. It was confirmed that treating the patient with hypomobile urethra (vector of bladder neck mobility: $\leq 5 \mathrm{~mm}$ ) compared to normomobile urethra (vector of bladder neck mobility: $5 \mathrm{~mm}<$ and $<15 \mathrm{~mm}$ ) was far more difficult, even if the surgery was individually planned. Achieving urinary continence was easiest in patients with hypermobile urethra (vector of bladder neck mobility: $\geq 15 \mathrm{~mm}$ ), even if suburethral tape was placed suboptimally [19].

In contrast to previous studies with PFS-TV [17-19], we focused on two points $(\mathrm{Cl}$ and $\mathrm{CII})$ with the intension to reflect separately the position and mobility of the internal urethral orifice. The results of our study confirmed a better validity of $\mathrm{Cl}$ over CII. Repeatability and reproducibility of the $\mathrm{Cl}$ point location and mobility was good and very good (0.6710-0.9961), while of the Cll point was medium, good and very good (0.5738-0.9944). It was possible to visualize $\mathrm{Cl}$ point in all the patients. The $\mathrm{Cll}$ visualization failed in $4.3-17.4 \%$ of cases.

The weakness of the study lies in lack of comparison with other methods of measuring urethral mobility including other ultrasound methods. However, we aimed to focus on PFS-TV. Also, it would not be feasible for the patient to endure a long ultrasound examination with many repetitions. Yet, a comparison with translabial pelvic floor ultrasound (transabdominal probe) should be performed in the future as a separate study.

Despite the weaknesses of this study, we believe the results confirm that PFS-TV is a useful method to evaluate position and mobility of urethra for both: clinical and research purposes.

\section{CONCLUSIONS}

The possibility to visualize point $\mathrm{Cl}$ in every single case with very good and good repeatability and reproducibility of measurements of this point's location and mobility, allows the usage of $\mathrm{Cl}$ as a universal reference point to evaluate 
bladder neck mobility and position during PFS-TV in clinical practice and research.

\section{REFERENCES}

1. Koelbl H, Nitti V, Baessler K. Pathophysiology of Urinary Incontinence, Faecal Incontinence and Pelvic Organ Prolapse. In: Abrams P, Cardozo L, Khoury S, Wein A. ed. Incontinence. Health Publication Ltd. 2009: 255-330.

2. Hosker G, Rosier P, Gajewski J. et al. Dynamic Testing. In: Abrams P, Cardozo L, Khoury S, Wein A. ed. Incontinence. Health Publication Ltd. 2009:413-522.

3. Tubaro A, Artibani W, Bartram C. et al. Imaging and Other Investigations. In: Abrams P, Cardozo L, Khoury S, Wein A. ed. Incontinence. Health Publication Ltd. 2009: 541-630.

4. Atherton MJ, Stanton SL. and colposuspension: comparison and contrast of possible mechanism. Neurourol Urodyn. 2000; 19: 396-398.

5. Staskin D, Kelleher C, Avery K. et al. Initial Assessment of Urinary and Faecal Incontinence in Adult Male and Female Patients. In: Abrams P, Cardozo L, Khoury S, Wein A. ed. Incontinence. Health Publication Ltd. 2009:331-412.

6. Smith ARB, Dmochowski R, Hilton P. et al. Surgery for Urinary Incontinence in Women. In: Abrams P, Cardozo L, Khoury S, Wein A. ed. Incontinence. Health Publication Ltd. 2009: 1191-1272.

7. Thorp JM, Jones LH, Wells E, et al. Assessment of pelvic floor function: a series of simple tests in nulliparous women. Int Urogynecol J Pelvic Floor Dysfunct. 1996; 7(2): 94-97, indexed in Pubmed: 8798094.

8. Shek KaL, Chantarasorn V, Dietz HP. The urethral motion profile before and after suburethral sling placement. J Urol. 2010; 183(4): 1450-1454, doi: 10.1016/j.juro.2009.12.028, indexed in Pubmed: 20171657.

9. Piskunowicz M, Świętoń D, Rybczyńska D, et al. Comparison of voiding cystourethrography and urosonography with second-generation contrast agents in simultaneous prospective study. J Ultrason. 2016; 16(67): 339-347, doi: 10.15557/JoU.2016.0034, indexed in Pubmed: 28138405.

10. Viereck V, Nebel M, Bader W, et al. Role of bladder neck mobility and urethral closure pressure in predicting outcome of tension-free vaginal tape (TVT) procedure. Ultrasound Obstet Gynecol. 2006; 28(2): 214-220, doi: 10.1002/uog.2834, indexed in Pubmed: 16858743.

11. Yang JM, Yang SH, Huang WC. Dynamic interaction involved in the tension-free vaginal tape obturator procedure. J Urol. 2008; 180(5): 20812087, doi: 10.1016/j.juro.2008.07.030, indexed in Pubmed: 18804224.

12. Yang JM, Yang SH, Huang WC. Correlation of morphological alterations and functional impairment of the tension-free vaginal tape obturator procedure. J Urol. 2009; 181(1):211-218, doi: 10.1016/j.juro.2008.09.033, indexed in Pubmed: 19013610.

13. WlaźlakE, Surkont G, Shek KaL, et al. Can we predict urinary stress incontinence by using demographic, clinical, imaging and urodynamic data? Eur J Obstet Gynecol Reprod Biol. 2015; 193: 114-117, doi: 10.1016/j. ejogrb.2015.07.012, indexed in Pubmed: 26291686.

14. Wlaźlak E, Kociszewski J, Suzin J, et al. Urethral length measurement in women during sonographic urethrocystography - an analysis of repeatability and reproducibility. J Ultrason. 2016; 16(64): 25-31, doi: 10.15557/JoU.2016.0003, indexed in Pubmed: 27104000.

15. Dietz HP, Eldridge $A$, Grace $M$, et al. Test-retest reliability of ultrasound assessment of bladder neck mobility. Int Urogynecol J. 2003; 14: 57-58.

16. Dietz HP, Eldridge A, Grace $M$, et al. Pelvic organ descent in young nulligravid women. Am J Obstet Gynecol. 2004; 191(1): 95-99, doi: 10.1016/j. ajog.2004.01.025, indexed in Pubmed: 15295348.

17. Kociszewski J, Rautenberg O, Kuszka A, et al. Can we place tension-free vaginal tape where it should be? The one-third rule. Ultrasound Obstet Gynecol. 2012; 39(2): 210-214, doi: 10.1002/uog.10050, indexed in Pubmed: 21793084.

18. Kociszewski J, Rautenberg O, Perucchini D, et al. Tape functionality: sonographic tape characteristics and outcome after TVT incontinence surgery. Neurourol Urodyn. 2008; 27(6): 485-490, doi: 10.1002/nau.20556, indexed in Pubmed: 18288705.

19. Wlaźlak E, Viereck V, Kociszewski J, et al. Role of intrinsic sphincter deficiency with and without urethral hypomobility on the outcome of tape insertion. Neurourol Urodyn. 2017 [Epub ahead of print], doi: 10.1002/nau.23211, indexed in Pubmed: 28139863.

20. Viereck V, Pauer HU, Hesse $\mathrm{O}$, et al. Urethral hypermobility after anti-incontinence surgery - a prognostic indicator? Int Urogynecol J Pelvic Floor Dysfunct. 2006; 17(6): 586-592, doi: 10.1007/s00192-006-0071-4, indexed in Pubmed: 16538422.

21. Tamborrini G, Marx C, Micheroli R. Inter-rater reliability in the classification of supraspinatus tendon tears using 3D ultrasound - a question of experience? J Ultrason. 2016; 16(66): 252-259, doi: 10.15557/JoU.2016.0025, indexed in Pubmed: 27679728.

22. Salvatore $S$, Serati $M$, Uccella $S$, et al. Inter-observer reliability of three different methods of measuring urethrovesical mobility. Int Urogynecol J Pelvic Floor Dysfunct. 2008; 19(11): 1513-1517, doi: 10.1007/s00192008-0671-2, indexed in Pubmed: 18604464.

23. Santoro GA, Wieczorek AP, Shobeiri SA, et al. Interobserver and interdisciplinary reproducibility of $3 \mathrm{D}$ endovaginal ultrasound assessment of pelvic floor anatomy. Int Urogynecol J. 2011; 22(1): 53-59, doi: 10.1007/s00192-010-1233-y, indexed in Pubmed: 20700728.

24. Santoro GA, Wieczorek AP, Dietz HP, et al. State of the art: an integrated approach to pelvic floor ultrasonography. Ultrasound Obstet Gynecol. 2011; 37(4): 381-396, doi: 10.1002/uog.8816, indexed in Pubmed: 20814874.

25. Masata J, Martan A, Svabik K, et al. Ultrasound imaging of the lower urinary tract after successful tension-free vaginal tape (TVT) procedure. Ultrasound Obstet Gynecol. 2006; 28(2): 221-228, doi: 10.1002/uog.2692, indexed in Pubmed: 16823766.

26. Dietz HP. Why pelvic floor surgeons should utilize ultrasound imaging. Ultrasound Obstet Gynecol. 2006; 28(5):629-634, doi: 10.1002/uog.3828, indexed in Pubmed: 17001745.

27. Caputo RM, Benson JT. The Q-tip test and urethrovesical junction mobility. Obstet Gynecol. 1993; 82(6): 892-896, indexed in Pubmed: 8233260. 